\title{
Ecstasy (MDMA, MDA, MDEA, MBDB) consumption, seizures, related offences, prices, dosage levels and deaths in the UK (1994-2003)
}

Fabrizio Schifano National Programme on Substance Abuse Deaths (nPSAD), St George's, University of London, London, UK. John Corkery National Programme on Substance Abuse Deaths (npSAD), St George's, University of London, London, UK. Paolo Deluca National Programme on Substance Abuse Deaths (nPSAD), St George's, University of London, London, UK. Adenekan Oyefeso National Programme on Substance Abuse Deaths (npSAD), St George's, University of London, London, UK. A Hamid Ghodse National Programme on Substance Abuse Deaths (nPSAD), St George's, University of London, London, UK.

\begin{abstract}
In the last decade, a global trend of escalating ecstasy (MDMA, MDA, MDEA, MBDB) use was observed. Mentions on medical death certificates, last year's ecstasy use, number of drug offenders, seizures, prices and dosage-levels figures were used for this descriptive and correlational study. Figures (1994-2003) were taken from the UK General Mortality Registers, from the Home Office Statistical Bulletins, from the British Crime Survey and from those reported to both the National Crime Intelligence and Forensic Science Services. A total of 394 ecstasy deaths mentions were here identified from the UK; in $42 \%$ of cases ecstasy was the sole drug mentioned. Overall, number of fatalities showed a year-peryear increase and positively correlated with: prevalence of last year's use $(p<0.01)$; number of offenders $(p<0.01)$ and number of seizures $(p<0.01)$ but negatively correlated with ecstasy price $(p<0.05)$. Price negatively correlated with: prevalence of last year's use $(p<0.001)$ and
\end{abstract}

number of seizures $(p<0.01)$; but positively correlated with average MDMA dosage per tablet $(p<0.01)$. MDA, MDEA and MBDB accounted for a significant proportion of tablets only up to 1997, but not afterwards. Increasing production with a concomitant decrease in ecstasy price may have facilitated an increase in consumption levels and this, in turn, may have determined an increase in number of ecstasy deaths mentions. Only medical death certificates and not coroners' reports at the end of their inquests were here analysed; no data were available in respect of other drugs use and toxicology results.

\section{Keywords}

MDMA, ecstasy deaths, ecstasy seizures, ecstasy prevalence of use, ecstasy offenders, ecstasy price

\section{Introduction}

In the second part of the 1990s, a global trend of escalating ecstasy use was observed. Although mostly identified with 3,4methylenedioxymethamphetamine (MDMA), tablets containing 3,4-methylenedioxyamphetamine (MDA), 3,4-methylenedioxyethylamphetamine (MDEA) and 2-methylamino-1-(3-4methylenedioxyphenyl)butane (MBDB) have been frequently referred to as 'ecstasy' as well (Schifano, 2001). Anecdotal reports have suggested that the use of ecstasy is an issue of concern across a number of different countries. Yacoubian (2003), in collecting data from three different sources to explore ecstasy use trends in the USA during the 1990s, confirmed that use of ecstasy has increased over time. According to Landry (2002), exposure to
MDMA among high school seniors in the USA has increased progressively and nearly quadrupled over the past decade. Both researchers were of the opinion that availability of MDMA and quantity seized by US law enforcement has increased dramatically during the 1990s, as have the number of MDMA-related arrests. Between 1995 and 1998, the lifetime prevalence of ecstasy use doubled to $5 \%$ of Australia's general population. Increase in the number of people using ecstasy, decline in the age of initiation, and growing popularity of ecstasy use among 'mainstream' people who do not fit the stereotype of an illicit drug user have all been described (Topp et al., 2004). Wilkins et al. (2003) examined changes in the use of ecstasy in New Zealand. Last year use of ecstasy increased from $1.5 \%$ in 1998 to $3.4 \%$ in 2001. In 2001 , $43 \%$ of users thought ecstasy was easier to obtain and $29 \%$ 
thought the price was lower compared with a year earlier. In Turkey, Corapcioglu and Ogel (2004) reported that while the percentage of those who used ecstasy at least once in their lifetime was $2.65 \%$ in 1998 , the figure reached $3.31 \%$ in 2001 .

Prevalence of recreational ecstasy use in Europe is not clearly defined; national surveys report lifetime prevalence of ecstasy use among males aged 15-24 years of 11-17\% in the Czech Republic, Spain, the Netherlands and the United Kingdom, and recent use rates of $5-13 \%$ in the Czech Republic, Spain, Ireland, Latvia, the Netherlands and the United Kingdom. It is likely that these figures would be even higher if only urban populations were considered (EMCDDA, 2004).

Over the last 5 years, among EU Member States, the United Kingdom has consistently been the country to seize most ecstasy (EMCDDA, 2004). Aust, Sharp \& Goulden (2002) provided a 'best' estimate of regular UK ecstasy users, which should be about 730000 (680000 in England and Wales; 30000 in Scotland and 20000 in Northern Ireland). Bramley-Harker (2001) calculated that the UK demand for ecstasy in 1998 was 26786000 tablets, although this was recognized to be probably an under-estimate. The ratio of occasional to regular users was 5:1. Self-selected respondents to postal surveys suggested that on average three to four tablets are consumed in a normal 'session' (Craske, 2002). Dividing Bramley-Harker's demand figure by four would suggest about 6.7 million ecstasy 'sessions' a year.

Most ecstasy consumption takes place at clubs, raves and other such venues (EMCDDA, 2004; Schifano, 2000). Clubbers' surveys show both more frequent use and elevated rates of consumption compared to the general population (Measham et al., 2001). Bellis et al. (2003) reported that proportions of Britons using ecstasy, cocaine and GHB whilst on holidays abroad have risen significantly between 1999 and 2002, as have numbers of ecstasy tablets taken on a usual night.

Although use trends are increasing, data regarding the hazards of MDMA are limited. Patel et al. (2004) obtained fatality reports from participating medical examiners in the United States. Thirtyeight $(8 \%)$ of the surveyed medical examiners reported 102 deaths associated with MDMA use from 1999 to 2001. Ten per cent of fatalities occurred in 1999 and 90\% thereafter, representing a $400 \%$ relative increase. The risk of 'overdose' with ecstasy has been described in the UK since the early 1990s (Henry et al., 1992). In England and Wales, a steady and constant increase of ecstasy (MDMA, MDA, MDEA)-related fatalities has been observed in the time frame August 1996-April 2002, when a total of 202 related deaths were recorded (Schifano et al., 2003a). A consistent decrease in the purchase costs of ecstasy tablets had been hypothesized, but not demonstrated, to be one of the significant factors for this increase in fatalities (Schifano, 2004).

Sumnall et al. (2004) investigated the influence of price upon hypothetical purchases of alcohol, amphetamine, cocaine and ecstasy for 43 current polysubstance misusers. Increasing the price of ecstasy significantly reduced the number of purchases. They found that purchases decreased at rates proportionally greater than the increases in prices. In assuming that drug use patterns follow the simulated purchases in their experiment, Sumnall et al. (2004) suggested that polysubstance misusers might alter their drug using behaviour based on the purchase price of the drugs available to them.

Six key indicator data sources (i.e. number of mentions on death certificates, last year's use, number of drug offenders, seizures, price, average MDMA dosage levels per tablet) were here deemed appropriate for contribution to a descriptive overview of ecstasy trends, which was the main aim of this study. Furthermore, we aimed at testing the hypothesis that these indicators were inter-related to each other. We hypothesized that ecstasy price fluctuations over the years inversely correlated with levels of ecstasy availability and numbers of ecstasy deaths.

\section{Methods}

This descriptive and correlational study covered the period January 1994 to December 2003. There are two main types of source in the UK for regular information on 'acute' drug-related deaths (DRDs): three General Mortality Registers (GMRs) and one Special Mortality Register (the National Programme of Substance Abuse Deaths (npSAD); Ghodse et al., 2004). The GMRs are the General Register Offices for England and Wales, Scotland, and Northern Ireland. Essentially, the mortality data recorded by these offices are derived from medical death certificates. No detailed information is passed to them on toxicology, e.g. levels of drugs and/or alcohol found in body tissues, blood or urine. Postmortem reports are not provided to the GMRs. Death figures were here obtained from the Office of National Statistics (ONS, including the General Register Office for England and Wales; Christophersen et al., 1998), from the General Register Office for Scotland (GROS; Jackson, 2004) and from the Department of Health, Social Services and Personal Safety for Northern Ireland, which has direct access to the data files at the General Register Office for Northern Ireland (GRONI). Figures given here were total mentions of ecstasy (i.e. MDMA, MDA, MDEA, MBDB) on medical death certificates for fatalities occurring in the years 1994-2003; separate figures for the four different molecules were not provided to us. Before 1994, these figures were not available for all parts of the UK. The total figures for each constituent country were added together to obtain UK figures. Different from here, previous UK ecstasy-related fatalities studies (Schifano et al., 2003a; Schifano et al., 2003b) analysed figures collected taking into account the npSAD (Ghodse et al., 2004) definition of ecstasy (MDMA, MDA, MDEA)-related deaths, with coroners' reports at the end of their inquests, and not death certificates, being analysed. Drug-related deaths using the standard definition employed by the Office of National Statistics (Griffiths, 2004) were as follows: ICD-10 codes F11-F16, F18, F19, X40-X44, X60-64, X85 and Y10-Y14. The number of persons dealt with for drug offences involving ecstasy; the number of seizures of ecstasy and the number of doses of ecstasy seized in the UK were taken from the Home Office Statistical Bulletins (Corkery, 2002; Ahmad and Mwenda, 2004). Data on number of seizures and number of doses seized were made available only for the period 1994-2002. Data on both average MDMA dosage levels per tablet and ecstasy content in terms of MDMA, MDA, MDEA, MBDB were based 
upon analyses carried out for the 1994-2001 period by the Forensic Science Service in part of the material seized by the UK police (Forensic Science Service, 2003). Information on last year use of ecstasy recorded by the British Crime Survey (BCS) was taken from the appropriate Home Office publications (Ramsay et al., 2001; Aust et al., 2002). The drug misuse self-completion component of the British Crime Survey asks about drug use (i.e. cocaine, crack, ecstasy, heroin, LSD, magic mushrooms and methadone) over the respondent's lifetime, in the last year and in the last month; the indicator presented here referred to respondents' use of ecstasy in the last year. Figures related to general household surveys conducted in England and Wales only and were the results for respondents age 16-29 for the sweeps in 1994, 1996, 1998 and 2000 and of 16-24 year olds in 2000/1 and 2002/3 (the age groups changed for the last two sweeps). The figures for intermediate years e.g. 1995 were the mid-point between the rates for the year preceding and year following e.g. 1994 and 1996. Prices were given in pounds sterling without any adjustment for inflation. They related to average UK street-level prices per tablet/dose of ecstasy as reported by police forces to the National Crime Intelligence Service (NCIS, 2002; Bellis et al., 2004) for the period 1994-2003. They were based on police officers asking dealers how much they charged and in some areas from test purchases.

To identify possible correlations between the different indicators, the Pearson coefficients were calculated.

\section{Results}

The total number of deaths where ecstasy (MDMA, MDA, MDEA, MBDB) was mentioned in the UK rose from 31 in 1994 to 78 in 2002, but dropped to 48 in 2003 . Over the years, ecstasy was involved in a total of 394 deaths and was the sole drug mentioned in $165(41.9 \%)$ occasions. In the remaining cases, ecstasy was mentioned together with other drugs and/or with alcohol. According to the UK BCS results, ecstasy last year use rose from $3 \%$ in 1994 to its peak (6.8\%) in 2001, before falling back to $5.4 \%$ in 2002-2003. In 2001, some 7370 individuals were cautioned by the police or dealt with by the courts for drug offences involving ecstasy-type drugs. This was a fourfold increase on the 1994 figure of 1881. The number of occasions on which ecstasy was seized within the UK by law enforcement agencies rose threefold (from 3614 to 10460) between 1994 and 2001. During the same period, the quantity of ecstasy (in terms of doses/tablets) seized rose fivefold (from 1598200 to 8030000 ). The price of ecstasy in the UK has fallen rapidly over the past decade. In 1994, the average price of a dose/tablet was $£ 16.50$, but by 2003 this figure had reduced by almost $70 \%$ to $£ 5.30$. If the effects of inflation are taken into account, the fall in real terms is even greater. The average MDMA dosage levels per tablet showed a decrease over the years, being about $100 \mathrm{mg}$ by $1994-1995$ and reducing to $74 \mathrm{mg}$ by $2000-2001$.

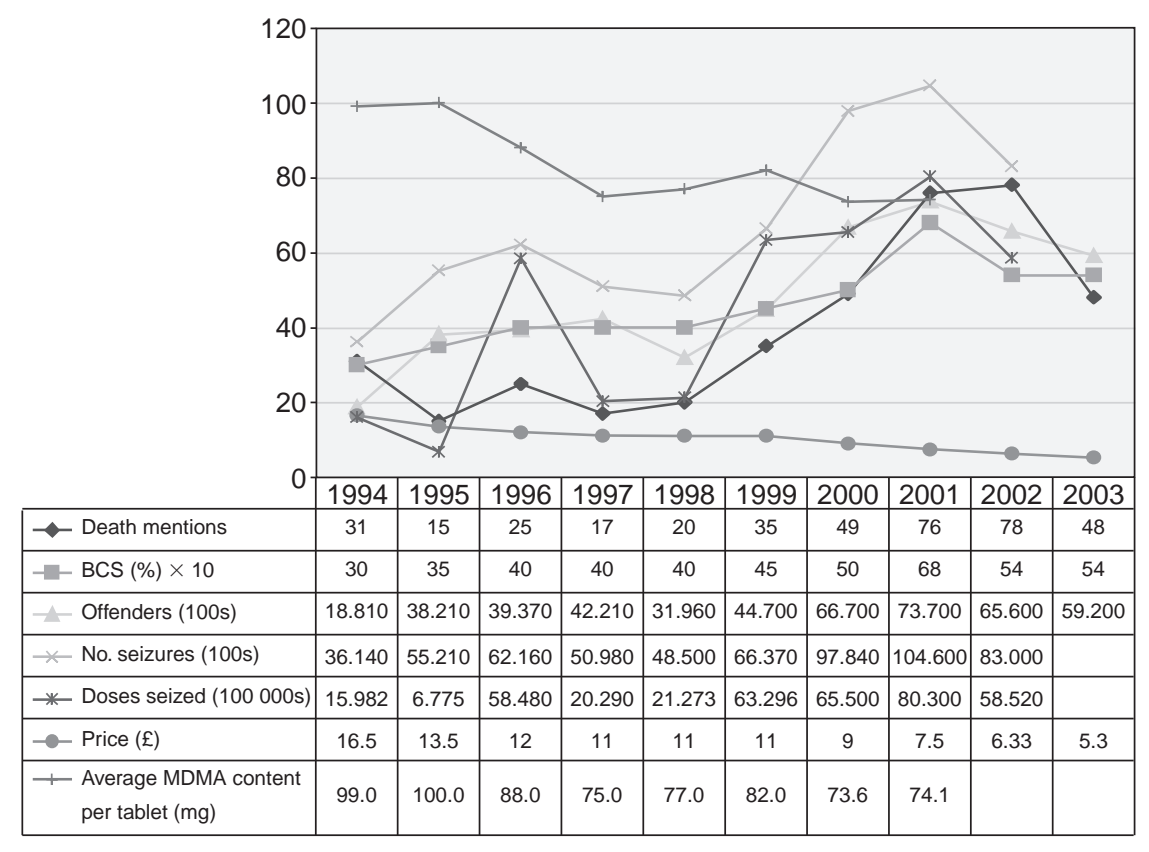

Figure 1 UK ecstasy trends, 1994-2003

Death mentions: provided by ONS, GROS and GRONI. BCS refers to respondents' ecstasy use in the last year; England and Wales only. The number of persons dealt with for drug offences involving ecstasy-type drugs; the number of seizures of ecstasy-type drugs and the number of doses of ecstasytype drugs seized in the UK were taken from the Home Office Statistical Bulletins. Ecstasy prices are given in $f$ sterling. Data on seizures were not made available for 2003. Data on average MDMA dosage levels per tablet were those reported by the Forensic Science Service and were not made available for 2002-2003. 
Table 1 Variation of 'ecstasy' tablets' content in terms of MDMA, MDA, MDEA and MBDB (UK; 1994-2003)

\begin{tabular}{|c|c|c|c|c|c|c|c|c|c|}
\hline \multirow[t]{2}{*}{ Years } & MDMA & $\%$ & MDA & $\%$ & MDEA & $\%$ & MBDB & $\%$ & Total \\
\hline & $\begin{array}{l}\text { Number of } \\
\text { ecstasy seizures } \\
\text { reported to the } \\
\text { Forensic Science } \\
\text { Service }\end{array}$ & & $\begin{array}{l}\text { Number of } \\
\text { ecstasy seizures } \\
\text { reported to the } \\
\text { Forensic Science } \\
\text { Service }\end{array}$ & & $\begin{array}{l}\text { Number of } \\
\text { ecstasy seizures } \\
\text { reported to the } \\
\text { Forensic Science } \\
\text { Service }\end{array}$ & & $\begin{array}{l}\text { Number of } \\
\text { ecstasy seizures } \\
\text { reported to the } \\
\text { Forensic Science } \\
\text { Service }\end{array}$ & & \\
\hline 1994 & 1966 & 75.1 & 132 & 5 & 520 & 19.9 & 0 & 0 & 2618 \\
\hline 1995 & 1835 & 52.4 & 282 & 8.1 & 1384 & 39.5 & 0 & 0 & 3501 \\
\hline 1996 & 530 & 47.3 & 36 & 3.2 & 501 & 44.7 & 53 & 4.7 & 1120 \\
\hline 1997 & 763 & 74.4 & 9 & 0.9 & 183 & 17.9 & 70 & 6.8 & 1025 \\
\hline 1998 & 1329 & 97.3 & 5 & 0.4 & 29 & 2.1 & 3 & 0.2 & 1366 \\
\hline 1999 & 2528 & 98.1 & 17 & 0.7 & 28 & 1.1 & 3 & 0.1 & 2576 \\
\hline 2000 & 5101 & 96.5 & 39 & 0.7 & 144 & 2.7 & 2 & 0.0 & 5286 \\
\hline 2001 & 6294 & 98.6 & 33 & 0.5 & 59 & 0.9 & 0 & 0 & 6386 \\
\hline 2002 & 5808 & 99.6 & 11 & 0.2 & 10 & 0.2 & 0 & 0 & 5829 \\
\hline 2003 & 6300 & 98.8 & 18 & 0.3 & 57 & 0.9 & 0 & 0 & 6375 \\
\hline
\end{tabular}

(Data were taken from analyses of ecstasy seizures reported by the UK Police to the Forensic Science Service).

With respect to variation of ecstasy tablets' content in terms of MDMA, MDA, MDEA and MBDB, it appeared that MDMA accounted for no more than $50-75 \%$ of ecstasy tablets in 1994-1997 but, after 1998, it was identified as the active ingredient in $97-100 \%$ of tablets. Before 1998, MDEA accounted for up to $45 \%$ of tablets whilst MDA and MDEA were respectively found in a range of $1-8 \%$ and $0-7 \%$ of the so-called ecstasy tablets.

Time series for ecstasy (MDMA) have been plotted against the following key indicators: number of death mentions, prevalence (England and Wales only; last year use from the British Crime Survey), number of persons found guilty or cautioned, number of seizures (UK), number of doses seized, price and average MDMA dosage levels per tablet as in Fig. 1. As can be seen from Table 1, Pearson correlation coefficients calculated were all significant. In particular, number of death mentions positively correlated with: prevalence of last year's use $(p<0.01)$; number of offenders $(p<0.01)$; number of seizures $(p<0.01)$ and number of doses seized $(p<0.05)$ but negatively correlated with ecstasy price $(p<0.05)$ over the years. Ecstasy price negatively correlated with: prevalence of last year's use $(p<0.001)$; number of offenders $(p<0.001)$; number of seizures $(p<0.01)$ and number of doses seized $(p<0.05)$ but positively correlated with average MDMA dosage level per tablet $(p<0.01)$.

\section{Discussion}

This report has provided a 10-year, UK-wide, ecstasy (MDMA, MDA, MDEA, MBDB) official figures data set. The findings of this study have confirmed the increase in ecstasy availability, consumption, offenders and deaths figures for the UK over the period
1994-2003 and have highlighted how these figures were negatively correlated with ecstasy price fluctuations over the years. On the other hand, over the period 1994-2001, ecstasy prices positively correlated with MDMA average dosage levels per tablet. Furthermore, results have shown that although in the mid-1990s MDEA, MDA and MBDB accounted for a significant proportion of tablets, since 1998, MDMA was identified as the only active compound in ecstasy tablets.

With respect to ecstasy deaths mentions, the UK results shown here are consistent with previous (1997-2000, Schifano et al., 2003a; August 1996-April 2002, Schifano et al., 2003b) findings from England and Wales. Ecstasy accounted for 1.2\% of all UK DRD deaths in 1997, but by 2001 and 2002 this proportion had risen to 4.1\% (Bellis et al., 2004; EMCDDA, 2004). On the other hand, the 2003 drop in ecstasy deaths mentions here reported is consistent with most recent EMCDDA (EMCDDA, 2004) and npSAD (Ghodse et al., 2004) findings.

There may be a few possible explanations, not necessarily contradicting each other, for the overall increase in number of ecstasy deaths mentions here observed. These include: larger availability of ecstasy in the UK with respect to most of the other European Union countries (EMCDDA, 2004); increase in ecstasy consumption in a polysubstance misuse context (Schifano, 2004); higher reporting rate, on the coroners' side, of ecstasy. A huge media interest surrounded some of the high profile cases of ecstasyrelated fatalities occurring in the mid-1990s in the UK and this may have increased awareness of drug intake possible consequences. In turn, this may have led to improved surveillance, monitoring and recording of the substance in investigations of sudden deaths of young people.

Previous analysis of npSAD ecstasy mortality data from England and Wales had suggested that ecstasy was the sole drug 
Table 2 Pearson correlation coefficients for the UK 'ecstasy' indicators, 1994-2003

\begin{tabular}{|c|c|c|c|c|c|c|c|c|}
\hline & & $\begin{array}{l}\text { Death } \\
\text { mentions }\end{array}$ & $\begin{array}{l}\text { Last year's use } \\
\text { prevalence } \\
\text { (England and } \\
\text { Wales only) }\end{array}$ & $\begin{array}{l}\text { Number of } \\
\text { offenders }\end{array}$ & $\begin{array}{l}\text { Number of } \\
\text { seizures }\end{array}$ & $\begin{array}{l}\text { Number of } \\
\text { seized } \\
\text { tablets/doses }\end{array}$ & Prices & $\begin{array}{l}\text { Average } \\
\text { MDMA } \\
\text { content per } \\
\text { tablet (mg) }\end{array}$ \\
\hline Death mentions & $\begin{array}{l}\text { Pearson } \\
\text { Sig. }\end{array}$ & 1 & & & & & & \\
\hline Last year's use prevalence & & & & & & & & \\
\hline (England and Wales only) & $\begin{array}{l}\text { Pearson } \\
\text { Sig. }\end{array}$ & $\begin{array}{l}0.854^{* *} \\
0.002\end{array}$ & 1 & & & & & \\
\hline Number of offenders & $\begin{array}{l}\text { Pearson } \\
\text { Sig. }\end{array}$ & $\begin{array}{l}0.815^{* *} \\
0.004\end{array}$ & $\begin{array}{l}0.930^{* *} \\
0.000\end{array}$ & 1 & & & & \\
\hline Number of seizures & $\begin{array}{l}\text { Pearson } \\
\text { Sig. }\end{array}$ & $\begin{array}{l}0.805^{* *} \\
0.009\end{array}$ & $\begin{array}{l}0.917^{* *} \\
0.001\end{array}$ & $\begin{array}{l}0.970^{* *} \\
0.000\end{array}$ & 1 & & & \\
\hline Number of seized tablets/doses & $\begin{array}{l}\text { Pearson } \\
\text { Sig. }\end{array}$ & $\begin{array}{l}0.749^{*} \\
0.02\end{array}$ & $\begin{array}{l}0.825^{* *} \\
0.006\end{array}$ & $\begin{array}{l}0.787^{*} \\
0.012\end{array}$ & $\begin{array}{l}0.853^{*} \\
0.003\end{array}$ & 1 & & \\
\hline Prices & $\begin{array}{l}\text { Pearson } \\
\text { Sig. }\end{array}$ & $\begin{array}{c}-0.710^{*} \\
0.021\end{array}$ & $\begin{array}{l}-0.862^{* *} \\
0.001\end{array}$ & $\begin{array}{c}-0.872^{* *} \\
0.001\end{array}$ & $\begin{array}{l}-0.825^{* *} \\
0.006\end{array}$ & $\begin{array}{c}-0.711^{*} \\
0.032\end{array}$ & 1 & \\
\hline $\begin{array}{l}\text { Average MDMA content } \\
\text { per tablet }(\mathrm{mg})\end{array}$ & Pearson & $\begin{array}{r}-0.454 \\
0.259\end{array}$ & $\begin{array}{r}-0.689 \\
0.059\end{array}$ & $\begin{array}{r}-0.672 \\
0.068\end{array}$ & $\begin{array}{r}-0.595 \\
0.120\end{array}$ & $\begin{array}{r}-0.564 \\
0.146\end{array}$ & $\begin{array}{l}0.878^{* *} \\
0.004\end{array}$ & 1 \\
\hline
\end{tabular}

$* * *$ Correlation is significant at the 0.001 level (2-tailed)

** Correlation is significant at the 0.01 level (2-tailed)

${ }^{*}$ Correlation is significant at the 0.05 level (2-tailed)

(Calculations related to seizures and MDMA average content per tablet referring respectively to 1994-2002 and 1994-2001 data only)

implicated in death in 7\% (Schifano et al., 2003a) to 17\% (Schifano et al., 2003b) of cases reported by coroners. According to the present figures from the UK General Mortality Registers (GMRs), ecstasy was the sole drug mentioned in the death certificate in $42 \%$ of the total number of related fatalities. The reason for the discrepancy in the data between the nPSAD and the GMRs may be due to the fact that the npSAD data capture system allows collection of fairly detailed information from coroners. As a consequence, a more precise description of the index ecstasy-related death is made possible and this may have decreased, in the npSAD mortality studies, the number of cases in which the compound was considered to be involved on its own.

Increase in ecstasy deaths mentions figures was positively correlated with levels of ecstasy availability indicators. Conversely, ecstasy price negatively correlated both with availability indicators, thus confirming the Sumnall et al. (2004) laboratory findings and death figures. This seems to provide some support to the most simple of the hypotheses, i.e. that the massive decrease in ecstasy price here observed over the years has facilitated an easier access to the drug and hence an increase in its consumption levels. This, in turn, has determined an increase in number of related fatalities. Increase in ecstasy consumption may cause a rise in number of deaths in at least two different ways. At the individual level, some consumers may binge with larger numbers of pills and this may be the cause of serious concern. Interestingly, ecstasy price decreased over the years in parallel with average MDMA dosage per tablet. The decrease in MDMA content per single tablet can determine an increase in number of tablets ingested. However, a small increase in MDMA dosage can lead to a disproportionate rise in drug plasma concentration ('non linear' pharmacokinetics; de la Torre et al., 2000). At the population level, on the other hand, an increase in consumption may well mean an increase in the number of individuals experimenting with ecstasy. In this way, it will be more likely that the minority of individuals which are hypothetically at higher risk of ecstasy acute medical sequelae will be approaching the compound. After acute ecstasy administration, a number of different physical complications have been reported: tachycardia, asystolia, arrhythmias, hypertension, metabolic acidosis, cerebral haemorrhages, convulsions, coma, rhabdomiolysis, mydriasis, vomiting, diarrhoea, thrombocytopoenia, disseminated intravascular coagulation, acute kidney failure (Landry, 2002; Sanjurjo et al., 2004; Schifano, 2004). The sympathomimetic stimulation may be exacerbated by the environmental condition (Parrott, 2001). Adverse effects of MDMA may be related to metabolism, which is regulated by the levels of the hepatic enzyme CYP2D6. About 5-9\% of Caucasians are deficient in this enzyme (Tucker et al., 1994), so that poor metabolizers may be at greater risk of toxic responses to the drug even at low doses (Ramamoorthy et al., 2002) but no data have confirmed these expectations so far (Gilhooly and Daly, 2002). The COMT enzyme is involved in the transformation of 3,4-dihydroxymethamphetamine-HHMA (the main MDMA metabolite) to 4hydroxy-3-methoxymethamphetamine-HMMA (Helmlin et al., 1996; Segura et al., 2001). Approximately $25 \%$ of the Caucasian 
population present low COMT activity (Zhu, 2002). HMMA may stimulate the release of the anti-diuretic hormone vasopressin so that excessive water retention, coupled with hyponatraemia, can be observed (Fallon et al., 2002; Forsling et al., 2002). Young women may be at greater risk (Parr et al., 1997; Budisavljevic et al., 2003). One could conclude that range of COMT activity (due to genetic polymorphism) may explain some of the inter-individual differences in vasopressin secretion after MDMA consumption.

Understandably, the amount of MDMA per tablet and the proportion of ecstasy tablets containing MDMA are central to any discussion of ecstasy acute detrimental effects. Data shown here are in general agreement with previous reports from the UK. Cole et al. (2002) analysed all tablets submitted to the Forensic Science Service in the north-west of England during 2001. All tablets submitted were found to include MDMA, whilst others contained MDEA as well and their content ranged from $20-109 \mathrm{mg}$ with the mean being in the $60-69 \mathrm{mg}$ range. Parrott (2004) found that, during the mid-1990s, the majority of ecstasy tablets contained MDMA while many others comprised MDA or MDEA. However, a small proportion comprised non-amphetamine drugs such as caffeine, ephedrine, ketamine, paracetamol or placebo. He suggested that, during the late $1990 \mathrm{~s}$, the proportion of ecstasy tablets containing MDMA increased to around $80-90 \%$ with non-MDMA tablets lately being very infrequent and characterized by purity levels between 90\% and 100\% (Parrott, 2004).

There are limitations with the information collected and published by the UK GMRs, such as the ONS, GROS and GRONI. The number of cases identified here were actually 'mentions' of ecstasy on death certificates, i.e. no information was available in respect to ecstasy and concomitant other drugs' dosage, post mortem reports, toxicology results and setting characteristics. Ecstasy inclusion on those documents submitted to GMRs did not necessarily mean that this drug directly 'caused' the death, but that ecstasy (MDMA, MDA, MDEA, MBDB) was found at postmortem and/or was identified by toxicological screening. A number of methodological problems can contribute to make it difficult to interpret the role ecstasy plays in the so-called 'ecstasyrelated' deaths and especially so if accurate information is not available. Polydrug abuse ingestion itself may act as a confounding factor; the suggested ecstasy/polydrug occasional user model is characterized by at least three different psychoactive compounds taken on the same occasion (Schifano, 2004). Cooccurrence of two stimulants (i.e. MDMA together with amphetamine and/or cocaine) might increase, in a synergic way, both the dopaminergic and serotonergic stimulation, so that the serotonin syndrome (Parrott, 2002) may be more likely to occur. Moreover, the mixed use of hallucinogens (i.e. ketamine and/or LSD together with MDMA) might increase the occurrence of intoxicated 'behaviours', such as dangerous driving, with a consequent higher risk of a fatal outcome (Schifano, 2004). Conversely, concurrent use of sedatives could somewhat mitigate the excess of sympathomimetic overactivity (Hunt, 2003). On the other hand, when ecstasy was mentioned on its own, one could assume that the substance recorded may have been more directly implicated in the fatality (Schifano et al., 2003a; Schifano et al., 2003b; Schifano, 2004).
A possible limitation of these data is given by reporting biases over time. In the first part of the 1990s, ecstasy may not have been screened for systematically. As a consequence, earlier years' figures shown here might be lower than real figures. Moreover, number of offenders and number of seizures may reflect changes in policies, priorities and activities of law enforcement agencies. The quantities of drugs seized over time may reflect both variations in intelligence-led activities of law enforcement agencies and a fluctuating availability of drugs on the black market.

One could argue that correlations between some of the variables were very high. In particular, there was a strong correlation between number of seizures and number of offenders. Although this may suggest that there may be some confounding variable underlying all the data, the nature of the relationships between the different variables is not straightforward and may change over time.

Although reports on ecstasy prices from the National Crime Intelligence Service are the best available from the UK, these data have their own limitations. Average prices are calculated from information submitted by individual officers from different police force areas, and at varying periods, on a non-systematic and nonstratified basis. Most information is probably anecdotal in nature and is not based on routine 'test purchases', although this is sometimes done by the Metropolitan Police.

Above limitations need to be borne in mind when looking at trends over time, but systematic monitoring of trends in illicit drug markets is imperative to provide the basis for effective practice in the health and law enforcement sectors (Topp et al., 2004). In particular, there is a need for routine/regular collection and analysis of detailed information on deaths associated with ecstasy. Further research should better describe the clinical implications of ecstasy misuse in the context of polydrug intoxication and should also specifically address the issue of possible individual psychobiological/genetic vulnerability to ecstasy deaths.

\section{Acknowledgements}

The deaths figures were obtained by John Corkery from Clare Griffiths at ONS (which includes the General Register Office for England and Wales), Graham Jackson at the General Register Office for Scotland and from Gillian Fegan who works for the Department of Health, Social Services and Personal Safety for Northern Ireland who has direct access to the data files at the General Register Office for Northern Ireland.

\section{References}

Ahmad M, Mwenda L (2004) Drug seizure and offender statistics, United Kingdom, 2001 and 2002. In Statistical Bulletin 8/04. Home Office Research Development and Statistics Directorate, London

Aust R, Sharp C, Goulden C (2002) Prevalence of drug use. In Key Findings from the 2001/2 British Crime Survey. Findings 182. Home Office Research Development and Statistics Directorate, London

Bellis M A, Hughes K, Bennett A, Thomson R (2003) The role of an international nightlife resort in the proliferation of recreational drugs. Addiction 98: 1713-1721

Bellis M A, Morleo M, Hughes S, McVeigh J, Lodwick A, Eaton G, Donnelly S (2004) Report to the EMCDDA by the Reitox National Focal Point. United Kingdom Drug Situation 2002. Department of Health, London 
Bramley-Harker E (2001) Sizing the UK market for illicit drugs. RDS Occasional Paper No 74. Home Office Research Development and Statistics Directorate, London

Budisavljevic M N, Stewart L, Sahn S A, Ploth D W (2003) Hyponatremia associated with 3,4-methylenedioxymethylamphetamine ('Ecstasy') abuse. Am J Med Sci 326: 89-93

Christophersen O, Rooney C, Kelly S (1998) Drug-related Mortality: Methods and Trends. Population Trends No 93, Autumn 1998. Office for National Statistics, London

Cole J C, Bailey M, Sumnall H R, Wagstaff G F, King L A (2002) The content of ecstasy tablets: implications for the study of their long-term effects. Addiction 97: 1531-1536

Corapcioglu A, Ogel K (2004) Factors associated with Ecstasy use in Turkish students. Addiction 99: 67-76

Corkery J M (2002) Drug seizure and offender statistics, United Kingdom, 2000, Home Office Statistical Bulletin 4/02. Home Office Research, Development and Statistics Directorate, London

Craske V, Robinson K, Harris I, Van der Buek J, Fielding A (2002) The Mixmag drug survey 2001. Mixmag 129: 84-109

de la Torre R, Farre' M, Roset P N, Hernandez Lopez C, Mas M, Ortuno J, Menoyo E, Pizarro N, Segura J, Cami J (2000) Pharmacology of MDMA in humans. Ann NY Acad Sci 914: 225-237

Department of Health (2002) Statistics from the Regional Drug Misuse Databases for Six Months ending March 2001. Statistical Bulletin 2002/7. Department of Health, London

European Monitoring Centre for Drugs and Drug Addiction; EMCDDA (2004) The state of the drugs problem in the European Union and Norway. Office for Official Publications of the European Communities, Luxembourg

Fallon J K, Shah D, Kicman A T, Hutt A J, Henry J A, Cowan D A, Forsling M (2002) Action of MDMA (ecstasy) and its metabolites on arginine vasopressin release. Ann N Y Acad Sci 965: 399-409

Forsling M L, Fallon J K, Shah D, Tilbrook G S, Cowan D A, Kicman A T, Hutt A J (2002) The effect of 3,4-methylenedioxymethamphetamine (MDMA, 'ecstasy') and its metabolites on neurohypophysial hormone release from the isolated rat hypothalamus. Br J Pharmacol 135: 649-656

Forensic Science Service (2003) Drug Abuse Trends, publication 1994-2003. Issues 103-113 (Old Series) and Issues 1-27 (New Series). Drugs Intelligence Unit, Forensic Science Service, Birmingham

Ghodse A H, Schifano F, Oyefeso A, Bannister D, Cobain K, Dryden R, Corkery J (2004) Drug-related deaths as reported by participating Procurators Fiscal and coroners in England, Wales, Northern Ireland, Scotland, Isle of Man, Guernsey and Jersey. Annual report 2004 and Surveillance Report No. 13. International Centre for Drug Policy, St George's Hospital Medical School, London

Gilhooly T C, Daly A K (2002) CYP2D6 deficiency, a factor in ecstasy related deaths? Br J Clin Pharmacol 54: 69-70

Griffiths C (2004) Deaths related to drug poisoning: England and Wales, 1998-2002. Hlth Stat Quart 21: 59-66

Helmlin H J, Bracher K, Bourquin D, Vonlanthen D, Brenneisen R (1996) Analysis of 3,4-methylenedioxymethamphetamine (MDMA) and its metabolites in plasma and urine by HPLC-DAD and GC-MS. J Anal Toxicol 20: 432-440

Henry J A, Jefferys K J, Dawling S (1992) Toxicity and deaths from 3,4methylenedioxymethamphetamine ('ecstasy'). Lancet 340: 384-387

Hunt N (2003) Ecstasy deaths. Did alcohol play a part? BMJ.com; Available from: http://bmj.bmjjournals.com/cgi/eletters/326/7380/80

Information and Statistics Division; ISD (1993) Scottish Drug Misuse Database Bulletin 1993. ISD Publications, Edinburgh
Information and Statistics Division; ISD (2003) Drug Misuse Statistics Scotland 2002. ISD Publications, Edinburgh

Jackson G W L (2004) Drug-related Deaths in Scotland in 2003. Occasional Paper. General Register Office for Scotland, Edinburgh

Landry M J (2002) MDMA: a review of epidemiological data. J Psychoactive Drugs 34: 163-169

Measham F, Aldridge J, Parker H (2001) Dancing on drugs: risk, health and hedonism in the British club scene. Free Association Books, London

National Crime Intelligence Service (2002) Streetwise publication 1994-2002. National Criminal Intelligence Service, London

Parr M J, Low H M, Botterill P (1997) Hyponatraemia and death after 'ecstasy' ingestion. Med J Aust 166: 136-137

Parrott A C (2001) Human psychopharmacology of Ecstasy (MDMA): a review of 15 years of empirical research. Hum Psychopharmacol Clin Exp 16: 557-577

Parrott A C (2004) Is ecstasy MDMA? A review of the proportion of ecstasy tablets containing MDMA, their dosage levels, and the changing perceptions of purity. Psychopharmacology (Berl) 173: 234-241

Patel M M, Wright D W, Ratcliff J J, Miller M A (2004) Shedding new light on the 'safe' club drug: methylenedioxymethamphetamine (ecstasy)-related fatalities. Acad Emerg Med 11: 208-210

Ramamoorthy Y, Yu A M, Suh N, Haining R L, Tyndale R F, Sellers E M (2002) Reduced (+/-)-3,4-methylenedioxymethamphetamine ('Ecstasy') metabolism with cytochrome P450 2D6 inhibitors and pharmacogenetic variants in vitro. Biochem Pharmacol 63: 2111-2119

Ramsay M, Baker P, Goulden C, Sharp C, Sondhi A (2001) Drug misuse declared in 2000: results from the British Crime Survey. Home Office Research Study 224. Home Office Research Development and Statistics Directorate, London

Robson P, Bruce M (1997) A comparison of 'visible' and 'invisible' users of amphetamine, cocaine and heroin: two distinct populations? Addiction 92: 729-1736

Sanjurjo E, Nogue S, Miro O, Munne P (2004) Analysis of patients attended in an emergency department due to ecstasy consumption. Med Clin (Barc) 123: 90-92

Schifano F (2000) Potential human neurotoxicity of MDMA ('Ecstasy'): subjective self-reports, evidence from an Italian drug addiction centre and clinical case studies. Neuropsychobiology 42: 25-33

Schifano F (2001) New trends in drug addiction: synthetic drugs; epidemiological, clinical and preventative issues. Epidemiol Psich Soc 10: $63-70$

Schifano F (2004) A bitter pill? Overview of ecstasy (MDMA; MDA) related fatalities. Psychopharmacol (Berl) 173: 242-248

Schifano F, Oyefeso A, Webb L, Pollard M, Corkery J, Ghodse A (2003a) Review of deaths related to taking ecstasy, England and Wales, 1997-2000. Br Med J 326: 80-81

Schifano F, Oyefeso A, Corkery J, Cobain K, Jambert-Gray R, Martinotti G, Ghodse AH (2003b) Death rates from ecstasy (MDMA, MDA) and polydrug use in England and Wales 1996-2002. Hum Psychopharmacol Clin Exp 18: 519-524

Segura M, Ortuno J, Farre M, McLure J A, Pujadas M, Pizarro N, Llebaria A, Joglar J, Roset P N, Segura J, de La Torre R (2001) 3,4-Dihydroxymethamphetamine (HHMA). A major in vivo 3,4-methylenedioxymethamphetamine (MDMA) metabolite in humans. Chem Res Toxicol l4: 1203-1208

Sumnall H R, Tyler E, Wagstaff G F, Cole J C (2004) A behavioural economic analysis of alcohol, amphetamine, cocaine and ecstasy purchases by polysubstance misusers. Drug Alcohol Depend 76: 93-99

Topp L, Breen C, Kaye S, Darke S (2004) Adapting the Illicit Drug Reporting System (IDRS) to examine the feasibility of monitoring 
trends in the markets for 'party drugs'. Drug Alcohol Depend 73: 189-197

Tucker G T, Lennard M S, Ellis S W, Woods H F, Cho A K, Lin L Y, Hiratsuka A, Schmitz D A, Chu T Y (1994) The demethylenation of methylenedioxymethamphetamine ('ecstasy') by debrisoquine hydroxylase (CYP2D6). Biochem Pharmacol 47: 1151-1156

Welsh Drug and Alcohol Unit and Drug Misuse Research Unit (WDAU and DMRU) (2001) Drug Misuse in Wales: A report from the Drug Misuse Database for the years 1999 and 2000. Welsh Drug and Alcohol Unit and Drug Misuse Research Unit, Manchester

Wilkins C, Bhatta K, Pledger M, Casswell S (2003) Ecstasy use in New
Zealand: findings from the 1998 and 2001 National Drug Surveys. N Z Med J 116: U383

Yacoubian G S Jr (2003) Tracking ecstasy trends in the United States with data from three national drug surveillance systems. J Drug Ed 33: $245-258$

Zhu B T (2002) Catechol-O-Methyltransferase (COMT)-mediated methylation metabolism of endogenous bioactive catechols and modulation by endobiotics and xenobiotics: importance in pathophysiology and pathogenesis. Curr Drug Metab 3: 321-349 